\title{
THE THYROID IN MALNUTRITION
}

\author{
BY \\ G. A. STIRLING* \\ From the Department of Pathology, University College of the West Indies, Jamaica
}

(RECEIVED FOR PUBLICATION JUNE 13, 1961)

Because the thyroid is concerned in metabolism and growth and is influenced by environmental factors it was thought that a morphological study of the thyroid of malnourished infants in a tropical country would be of interest.

\section{Methods and Materials}

The weight of the thyroid was estimated in 125 Jamaican negro infants aged 3 months to 3 years. The nutritional state of most of the infants was easy to assess, but in a few instances it had to be decided by paying attention to the social and dietary history and by comparing heights and weights with percentile values quoted by Stuart and Stevenson (1950). Of the 125 infants, 56 were judged to be malnourished and 69 relatively well nourished. The malnourished infants included examples of kwashiorkor and marasmus, and cases showing features of both conditions.

The thyroids were removed soon after death or obtained from refrigerated cadavers. They were dissected clean of fat and connective tissue and weighed on an analytical balance.

In order to plot the growth of the gland an additional 25 thyroids from foetuses and infants under 3 months were dissected and weighed.

Increasing the time between death and fixation of the thyroid by removing portions of thyroid from the cadaver at varying times led to loss of colloid and desquamation of epithelium in many, but not in all, thyroids. Therefore the histological appearances were studied in a further $\mathbf{5 0}$ thyroids removed within four hours of death. These thyroids were not weighed or dissected but fixed immediately in $10 \%$ formol-saline to avoid possible artefacts due to autolysis and handling. Paraffin sections were cut at $5 \mu$ and stained with haematoxylin and eosin. Other stains were tried but found to be unhelpful. Of these 50 infants, 29 were judged to be malnourished and 21 relatively well nourished.

* Present address: Department of Pathology, Royal Free Hospital, Gray's Inn Road, London W.C.1.

\section{Results}

The average weight of the thyroid was lower in the malnourished than in the relatively well nourished (Fig. 1).

The average weight of the thyroid in both groups was lower than in the British and American infant (Fig. 1). The thyroid weight in the foetus was approximately half that given by Potter (1952) for infants born in Chicago.

The Jamaican foetal thyroid weights are given below:

\begin{tabular}{c|c}
\hline $\begin{array}{c}\text { Thyroid Weight } \\
(\mathrm{g} .)\end{array}$ & $\begin{array}{c}\text { Foetus Weight } \\
\text { (g.) }\end{array}$ \\
\hline $0 \cdot 22$ & 500 \\
$0 \cdot 36$ & 1,000 \\
$0 \cdot 86$ & 2,000 \\
0.90 & 3,000 \\
\hline
\end{tabular}

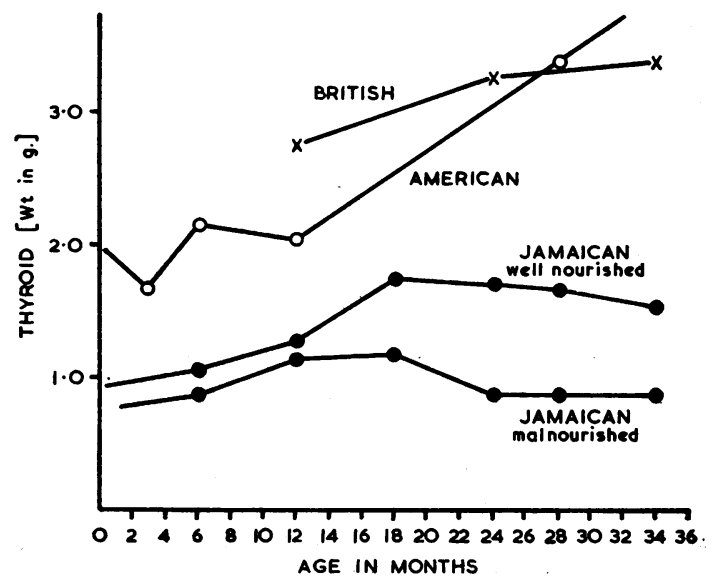

FIG. 1.-The weight of the thyroid in relatively well-nourished and malnourished Jamaican infants as compared with British and American infants. The British thyroid weights are calculated as $0 \cdot 27$ per $1,000 \mathrm{~g}$. body weight (Korenchevsky, 1942). The American weights are those of Spector (1956). Some of these are given as averages for a whole year. 
A variety of histological appearances was seen, sometimes in the same thyroid. However, four main patterns could be distinguished.

Resorptive: tall columnar epithelium and thin colloid.

Secretory: cuboidal epithelium usually with colloid of varying density.

Inactive: flat or low cuboidal epithelium and dense colloid.

Depleted: columnar or high cuboidal epithelium and absent colloid.

The number of each pattern in the two groups of infants is given in the Table.

TABLE

\begin{tabular}{ccc|c|c}
\hline & & & Malnourished & Well Nourished \\
\hline Resorptive & $\ldots$ &. & 3 & - \\
Secretory & $\ldots$ & $\ldots$ & 9 & 9 \\
Inactive . & $\ldots$ & $\ldots$ & 12 & 10 \\
Depleted &. &. & 5 & 2 \\
\hline Total &. &. & 29 & 21 \\
\hline
\end{tabular}

\section{Discussion}

The difference in the size of the thyroid in the Jamaican as compared with the British and American infant (Fig. 1) is probably due to environmental and racial factors. The majority of the Jamaican infants came from the warm coastal plain area of Kingston and were of mainly African descent. This difference in size is also seen in the Jamaican foetal thyroid which is approximately half the weight quoted by Potter (1952) for infants born in Chicago. Ekholm and Niemineva (1950) described the thyroid in Scandinavia as weighing 1.65 to $3 \cdot 18 \mathrm{~g}$. in foetuses of $1,250 \mathrm{~g}$. to $2,500 \mathrm{~g}$. In Jamaican infants the thyroid has not usually attained this weight even in the third year of life.

In the malnourished infant the smaller thyroid was due to a failure of growth, although in a few instances the presence of fibrous tissue and a sparsity of follicles suggested atrophy. Although growth was retarded, differentiation was normal and the foetal appearances were not seen. Extra-acinar proliferations of undifferentiated epithelium were more common in thyroids from malnourished infants, and it was tempting to regard these as foetal remnants. However, serial sections showed that the majority of these, as reported by Moritz (1931), were extra-acinar buds or acini cut tangentially. The reason why the thyroid failed to increase in size in the relatively well-nourished infants over the age of 18 months is not known.

The thyroids of both groups of infants could be classified according to their histological appearances as resorptive, secretory, inactive and depleted.
The first three patterns were similar to those described in the adult by Goormaghtigh and Thomas (1934). In this classification one criterion is the height of the follicular epithelium; this has been shown by Abel (1940) to be an index of functional activity. In both the malnourished and wellnourished infants a majority of thyroids were in an inactive or secretory phase and showed similar histological appearances. The appearances in two of the more severely malnourished infants are shown in Figs. 2, 3, 4 and 5. Considering that the thyroid is intimately concerned in metabolism, the absence of any marked histological evidence of altered functional activity is surprising. It could be argued that the morphology of the thyroid does not reflect its functional state, but there is evidence from both human and animal material that disturbances of thyroid activity result in histological change. Therefore, the most acceptable explanation is that thyroid function in malnutrition is usually unchanged. This thesis receives some support from an observation of S. Montgomery (1961, personal communication) that radioactive iodine excretion is unchanged in the malnourished infant.

According to Stephens (1940) undernutrition in the experimental animal leads to retention of colloid and flattening of the acinar epithelium. These appearances were common in the peripheral acini of many thyroids regardless of the nutritional state. Similar changes were seen affecting most, but not all, of the acini in eight of the malnourished infants and were also seen in two of the well-nourished infants.

All the infants had infections of varying severity, so that in this respect the control series was still valid. The effect of infection on the thyroid is difficult to evaluate, but Cole, Womack and Gray (1929) have described changes including loss of colloid with desquamation of acinar epithelium. I was able to produce these changes by lengthening the death-fixation interval; they should, therefore, be interpreted with caution. The thyroids described as 'depleted' were probably exhausted in that they showed tall intact acinar epithelium with either absent colloid or a few nubbins of thick colloid surrounded by large cells which were probably macrophages. It is possible that the extra demands made on the thyroid by the presence of infection resulted in these appearances.

Handler (1948) has shown that in the experimental animal hypothyroidism leads to an increased liver fat content. As the pathogenesis of fatty liver in the malnourished is not understood, an attempt was made by histology to see if there was any correlation between the fat content of the liver and the state of the thyroid. None was found. 

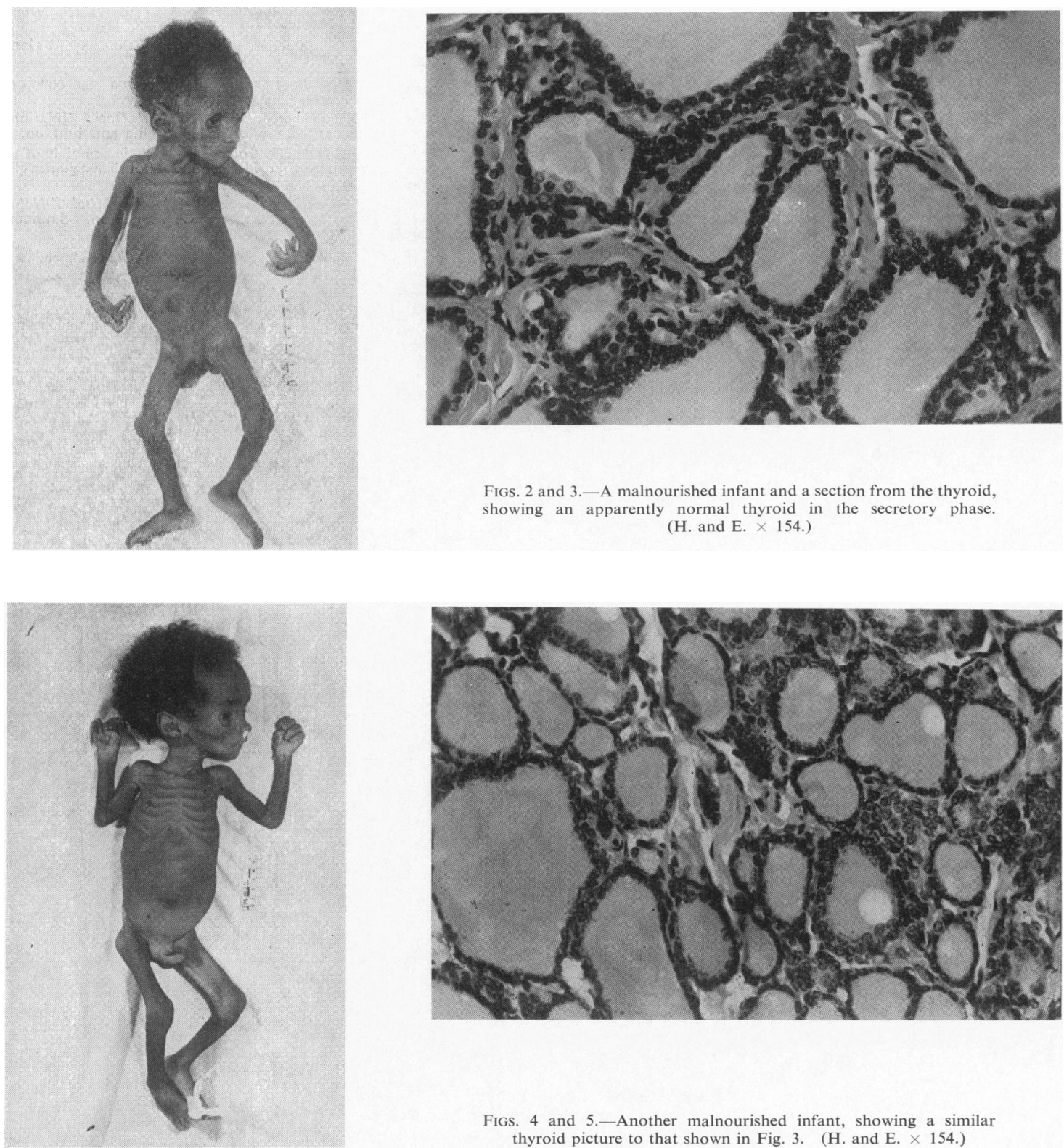

Figs. 2 and 3.-A malnourished infant and a section from the thyroid, showing an apparently normal thyroid in the secretory phase. (H. and E. $\times$ 154.)

\section{Summary}

The average weight of the thyroid is lower in the Jamaican than in the British and American infant. The Jamaican foetal thyroid is smaller than the American foetal thyroid.

The thyroid is smaller in the malnourished than in the relatively well nourished, but differentiation is normal and foetal appearances are not seen.

A surprising absence of histological change suggests that thyroid function may be unchanged even in fatal cases of malnutrition.

No correlation was found between the amount of fat in the liver and thyroid activity as assessed histologically. 


\section{REFERENCES}

Abel, M. S. (1940). A quantitative study of the height of thyroid acinar cells in normal and abnormal thyroids. Amer. J. med. acinar cells in
Sci., $200,220$.

Cole, W. H., Womack, N. A. and Gray, S. H. (1929). The thyroid in infections and toxemias; pathological changes in the human gland. Amer. J. Surg., 6, 221.

Ekholm, E. and Niemineva, K. (1950). On prenatal changes in the relative weights of the human adrenals, the thymus and the thyroid gland. Acta paediat. (Uppsala), $39,67$.

Goormaghtigh, N. and Thomas, F. (1934). The functional reactions of the human thyroid. Amer. J. Path., 10, 713.

Handler, P. (1948). The influence of thyroid activity on the liver and plasma lipides of choline- and cystine-deficient rats. J. biol. Chem., 173, 295.
Korenchevsky, V. (1942). Natural relative hypoplasia of organs and the process of ageing. J. Path. Bact., 54, 13.

Moritz, A. R. (1931). Interacinar epithelium of the thyroid gland. Amer. J. Path., 7, 37.

Potter, E. L. (1952). Pathology of the Fetus and the Newborn. Year Book Publishers, Chicago.

Spector, W. S. (1956). Handbook of Biological Data. [National Academy of Sciences.] Saunders, Philadelphia and London.

Stephens, D. J. (1940). The effect of the thyrotropic principle of the anterior pituitary on the thyroid of the undernourished guinea-pig. Endocrinology, 26, 485.

Stuart, H. C. and Stevenson, S. S. (1950). In Mitchell-Nelson Textbook of Pediatrics, 5th ed., ed. W. E. Nelson. Saunders, Textbook of
Philadelphia. 